EDITOR'S

${ }^{1}$ Monash Centre for Occupational \& Environmental Health, Department of Epidemiology \& Preventive Medicine, Monash University, Melbourne, Australia;

${ }^{2}$ Australian Government Department of Veterans' Affairs, Canberra, Australia; ${ }^{3}$ National Research Centre for Environmental Toxicology, The University of Queensland, Brisbane, Australia; ${ }^{4}$ Cancer Institute New South Wales, Eveleigh, Australia; ${ }^{5}$ John Curtin School of Medical Research, The Australian National University, Canberra, Australia

Correspondence to:

Dr J Ikin, Monash University School of Public Health and Preventive Medicine, The Alfred, Commercial Road, Melbourne, VIC 3004, Australia; Jill.ikin@ med.monash.edu.au

License statement: The Corresponding Author has the right to grant on behalf of all authors and does grant on behalf of all authors, a nonexclusive licence on a worldwide basis to the BMJ Publishing Group Ltd and its licensees, to permit this article (if accepted) to be published in JECH and any other BMJ Group products and to exploit all subsidiary rights, as set out in our licence (http:// jech.bmijournals.com//ifora/ licence.pdf). The parties agree that copyright in the article vests with the Commonwealth of Australia and is to be acknowledged as

follows: (C) Commonwealth of Australia 2008.

Accepted 24 June 2007

\title{
Life satisfaction and quality in Korean War veterans five decades after the war
}

\author{
J F Ikin, ${ }^{1}$ M R Sim, ${ }^{1}$ D P McKenzie, ${ }^{1}$ K W A Horsley, ${ }^{2}$ E J Wilson, ${ }^{2}$ W K Harrex, ${ }^{2}$ \\ M R Moore, ${ }^{3} \mathrm{P} L$ Jelfs, ${ }^{4} \mathrm{~S}$ Henderson ${ }^{5}$
}

\begin{abstract}
Background: Military service is considered to be a hidden variable underlying current knowledge about wellbeing in the elderly. This study aimed to examine life satisfaction and quality of life in Australia's surviving male Korean War veterans and a community comparison group, and to investigate any association with war deploymentrelated factors.
\end{abstract}

Methods: Participants completed a postal questionnaire which included the Life Satisfaction Scale, the brief World Health Organization Quality of Life (WHOQOL-Bref) questionnaire and the Combat Exposure Scale.

Results: Korean War veterans reported significantly lower Percentage Life Satisfaction (PLS) and quality of life scores on four WHOOOL-Bref domains, compared with similarly aged Australian men (each $p$ value $<0.001$ ). These outcomes were most strongly associated with severity of combat exposure and low rank. Mean PLS was approximately $15 \%$ lower in veterans who reported heavy combat compared with those reporting no combat, and approximately $12 \%$ lower in enlisted ranked veterans compared with officers.

Conclusions: Fifty years after the Korean War, life satisfaction and quality in Australian veterans is poor relative to other Australian men, and is associated with deployment-related factors including combat severity and low rank. In order to respond effectively to current and projected population health needs, nations with large veteran populations may need to consider the impact of military service on well-being in later life.

With declining mortality rates and increased life expectancy leading to ageing populations in many nations, governments are increasingly prioritising the improved health and well-being of the elderly among their national goals. ${ }^{12}$ In order that such goals be achieved, important life course determinants of health and well-being in the elderly must be considered. Military service is considered a significant "hidden variable" underlying current knowledge about ageing. ${ }^{3}$ Many major studies of ageing have failed to include military veteran status in their investigations ${ }^{4}$ despite the high prevalence of war service among elderly cohorts (for example, it has been estimated that $76 \%$ of United States men aged 70-74 are war veterans ${ }^{5}$ ) and an existing veteran literature showing longterm adverse physical, psychological and socioeconomic consequences of war service. ${ }^{6-11}$

Few studies have investigated the unique effects of the Korean War, in particular, on well-being in elderly veteran survivors. Korean War veterans have sometimes been included as relatively small subgroups among larger cohorts of Second World
War ${ }^{7}$ or Vietnam War veterans, ${ }^{12}$ while other studies have grouped veterans of various conflicts together. ${ }^{913}$ Before two recent studies showing increased mortality ${ }^{14}$ and cancer incidence ${ }^{15}$ in Australia's Korean War veterans, there were no major investigations of the impact of war service upon health or well-being in large groups of this Australian veteran population.

This study explores the association between quality of life, life satisfaction and war service in Australia's surviving male Korean War veterans compared with Australian men who were not involved with that war. Part of a larger investigation that found substantial psychological morbidity in these veterans, ${ }^{16}$ this study explores several domains of quality of life and well-being including satisfaction with life as a whole, perception of general physical and psychological health status, social relationships and the adequacy of environment. Aspects of Australian Korean War service, including age and rank at deployment, being wounded in action and severity of combat exposure are investigated for their association with quality of life 50 years after the war.

\section{METHODS}

This study was approved by the Monash University and Australian Government Department of Veterans' Affairs (DVA) human research ethics committees.

\section{Recruitment}

Recruitment methods, participation rates and resulting participant profiles with regard to demographics and Korean War service characteristics have been described and tabulated in greater detail previously ${ }^{16}$ and are only briefly summarised again here.

Recruitment was via mailed invitation to complete a self-report questionnaire, with two further mailings to non-responders. The invited Korean War veteran group was 7525 men; the survivors, residing in Australia, of 17814 male Australian armed forces personnel deployed to Korea between June 1950 and April 1956. The comparison group, defined as Australian men of similar age to the Korean War veterans who were resident in Australia at the time of the Korean War but who did not serve in that conflict, were drawn from a sample of 2964 Australian men aged 65 and over randomly selected from the Australian Electoral Roll and invited to participate. Because voting and Electoral Roll registration is compulsory in Australia, the Electoral Roll provides a reasonably 
complete sampling frame of adult Australians. Responses to questionnaire items were used to identify a subgroup (the comparison group) who were Australian born or had arrived and settled in Australia by the end of 1955.

Completed questionnaires were returned by 6122 (81.4\%) veterans and 1893 (63.9\%) of the Electoral Roll sample. A subgroup of 1510 (79.8\%) Electoral Roll participants met eligibility for inclusion as the comparison group. The mean age in both study groups was very close to 75 years, and participants ranged in age from approximately 66 to 99 years old. The Korean War veterans were slightly less likely to be married or in a de facto relationship (71\% vs. $77 \%$ ) or university educated (4\% vs. $7 \%$ ).

\section{Korean War deployment characteristics}

Fifty-six per cent of the participating veterans were aged 2125 years at the time of their first Korean War deployment, and $29 \%$ were in their first or second year of military service. Fiftyfour per cent served with the Army, 38\% with the Navy and 8\% with the Air Force, and $74 \%$ served under an enlisted rank, while $19 \%$ and $7 \%$, respectively, were non-commissioned officers (NCOs) or officers.

The group averaged a total of 285 days of deployment to Korea. For $45 \%$, the Korean War was the only major military conflict to which they deployed, whereas others reported involvement in conflicts such as the Second World War and the 1950-1960 Malayan Emergency.

Being wounded in action during the Korean War was reported by 871 (14\%) participating veterans. Approximately one quarter of these sustained injuries that were treated at a local aid post such as a sick bay or field ambulance before return to duties (labelled "evacuation type 1"); a quarter reported evacuation to a local field or ship hospital before return to duties ("evacuation type 2"); a quarter reported evacuation to a hospital in Japan before return to duties ("evacuation type 3"); and a quarter reported evacuation to Japan and then to Australia, without return to duties in Korea ("evacuation type 4"). Each increase in category of evacuation, from type 1 to type 4, is considered likely to represent an increase in injury severity.

\section{Measures}

The self-report questionnaire included the Life Satisfaction Scale, ${ }^{17}$ the 26-item World Health Organization Quality of Life questionnaire (WHOQOL-Bref), ${ }^{18}{ }^{19}$ some demographic questions, the Combat Exposure Scale $(\mathrm{CES})^{20}$ and questions concerning the year that Korean War veterans first joined the Australian armed forces, any deployment to other major military conflicts, whether or not wounded in action during the Korean War deployment and any associated treatment or evacuation.

The Life Satisfaction Scale, which assesses satisfaction with life in general, ${ }^{17}$ has been reported to perform well in large population-based studies ${ }^{21}$ and have satisfactory psychometric properties. ${ }^{17} 22$ The scale's single question ("How do you feel about your life as a whole, taking into account what has happened in the last year and what you expect to happen in the future?") has seven possible responses (see figure 1). The raw scores (S), ranging from 1 to 7 , were converted by applying the linear transformation $100(7-S) / 6$ and presented as "percentage life satisfaction" (PLS). ${ }^{21}{ }^{23}$ These transformed scores range from 0 (zero) to 100 with higher scores representing higher life satisfaction.
The WHOQOL-Bref ${ }^{18}{ }^{19}$ contains two individual questions exploring overall self-rated quality of life and satisfaction with health, and 24 questions that explore the four domains of physical health, psychological health, social relationships and the environment. Domain scores range from 4 to 20 with higher scores denoting higher quality of life. ${ }^{18} 19$ Domain scores have been shown to demonstrate satisfactory discriminant validity between ill and well subjects, internal consistency and testretest reliability. ${ }^{19}$

The seven-item CES, ${ }^{20}$ used to measure the severity of combat experience during Korean War deployment, is a widely used measure of combat exposure in war veterans. ${ }^{324-29}$ Final scores on the CES are divided into six categories of combat severity ranging from no combat to heavy combat. ${ }^{3} 20$

Data on additional Korean War service characteristics, such as service branch, rank, date of first deployment to Korea, age at deployment and duration of deployment, were obtained from records maintained by the DVA. Date of first deployment to Korea was used to categorise veterans into three deployment eras: (1) those who first deployed during what is termed the "mobile phase" from the commencement of the war in June 1950 to the end of June 1951 - this phase is characterised by many significant and bloody offensives and counter-offensives taking place over long distances along a moving front line; (2) those who first deployed during the "static phase" of the war between July 1951 and late July 1953-a period of armistice negotiation, but also ongoing hostility on a fairly static front that eventually became the ceasefire line; and (3) those who first deployed after the armistice was signed on 27 July 1953.

\section{Statistical analysis}

Statistical analyses were performed using SPSS version $11.5^{30}$ and Stata version 8.0. ${ }^{31}$ The age distribution of the Electoral Roll-based comparison group participants ( $18 \%$ aged $<70$ years, $64 \% 70-79$ years and 18\% 80+ years) differed from that of the Korean War veteran participants ( $6 \%$ aged $<70$ years, $85 \% 70$ 79 years and $9 \% 80+$ years). Weighting factors, based on the proportions of participants in 5-year age bands in each group, were therefore applied to the results of the comparison group participants to correct for the difference in age distribution between this group and the participating veterans.

Mean and standard deviation (SD) scores on the WHOQOLBref and Life Satisfaction Scale were compared between groups after applying the weighting factor to the results of the comparison group participants. Differences between unweighted means were then analysed using multiple linear regression, ${ }^{32}$ first adjusting for current age and subsequently adjusting for additional potential confounding factors.

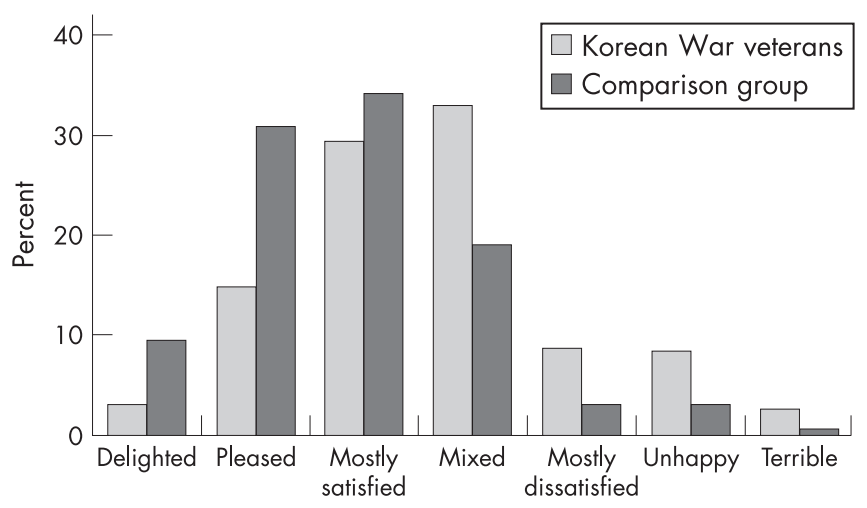

Figure 1 Life Satisfaction Scale responses. 
Table 1 Mean Percentage Life Satisfaction and WHOQOL-Bref scores

\begin{tabular}{|c|c|c|c|c|c|c|c|c|}
\hline & \multicolumn{2}{|c|}{$\begin{array}{l}\text { Korean War veterans } \\
N=6122^{*}\end{array}$} & \multicolumn{2}{|c|}{ Comparison group $\mathrm{N}=1510 *$} & \multirow{3}{*}{$\begin{array}{l}\text { Age-adjusted } \\
\text { mean } \\
\text { difference } \dagger\end{array}$} & \multirow{3}{*}{$\begin{array}{l}\text { Multivariate } \\
\text { adjusted mean } \\
\text { difference }\end{array}$} & \multirow[b]{3}{*}{$95 \% \mathrm{CI}$} & \multirow[b]{3}{*}{ p Value } \\
\hline & \multirow[b]{2}{*}{ Mean } & \multirow[b]{2}{*}{ (SD) } & \multicolumn{2}{|c|}{ Weighted } & & & & \\
\hline & & & Mean & (SD) & & & & \\
\hline Percentage Life Satisfaction & 55.81 & $(21.75)$ & 68.96 & $(19.15)$ & -12.77 & -12.03 & -13.27 to -10.79 & $<0.001$ \\
\hline \multicolumn{9}{|l|}{ WHOQOL-Bref } \\
\hline 01. Quality of life & 3.25 & $(1.02)$ & 4.01 & $(0.86)$ & -0.74 & -0.70 & -0.76 to -0.65 & $<0.001$ \\
\hline 02. Satisfaction with health & 2.98 & $(1.10)$ & 3.69 & $(1.02)$ & -0.70 & -0.68 & -0.74 to -0.62 & $<0.001$ \\
\hline Domain 1 (physical health) & 12.13 & (3.48) & 14.93 & $(3.10)$ & -2.76 & -2.66 & -2.86 to -2.46 & $<0.001$ \\
\hline Domain 2 (psychological) & 13.55 & $(2.93)$ & 15.58 & $(2.26)$ & -1.99 & -1.89 & -2.05 to -1.72 & $<0.001$ \\
\hline $\begin{array}{l}\text { Domain } 3 \text { (social } \\
\text { relationships) }\end{array}$ & 13.08 & $(3.35)$ & 15.02 & $(2.89)$ & -1.91 & -1.81 & -2.00 to -1.62 & $<0.001$ \\
\hline Domain 4 (environment) & 14.82 & $(2.51)$ & 16.24 & $(2.15)$ & -1.40 & -1.30 & -1.44 to -1.16 & $<0.001$ \\
\hline
\end{tabular}

*Actual $\mathrm{N}$ from which each mean and SD score is derived varies by up to $2 \%$ fewer participants depending on the number of respondents to individual questions.

$\dagger$ This difference between means is adjusted for age (65-69 years; 70-74 years; 75-79 years; 80-84 years; 85+ years).

\$This difference between means and associated $95 \% \mathrm{Cl}$ and p value is adjusted for age (65-69 years; 70-74 years; 75-79 years; 80-84 years; 85+ years), education (primary; any secondary up to grade 10; grades 11, 12 or certificate; diploma or university), marital status (married or de facto; widowered; divorced or separated; single, never married) and country of birth (Australia; other).

Differences across subgroups of veterans according to deployment characteristics were modelled using linear regression. Mean differences and their associated 95\% confidence intervals $(95 \% \mathrm{CI})$ and significance tests were first obtained using raw scores and then calculated with adjustment for potential confounding factors.

For some deployment characteristics (exposures), the existence and magnitude of response trends across exposure categories were also computed, using the exposure categories as linear variables in the regressions.

\section{RESULTS}

Responses to the Life Satisfaction Scale, completed by 6062 (99.0\%) veterans and 1506 (99.7\%) comparison group participants, are shown in figure 1 . In relation to their life as a whole, recent past and future, veterans were less likely than the comparison group to report feeling delighted, pleased or mostly satisfied, and more likely to report feeling mostly dissatisfied, unhappy or terrible.

Percentage Life Satisfaction (PLS) mean and SD scores are shown in table 1 . Veterans recorded significantly poorer PLS scores (mean PLS $=56$ ) than the comparison group (mean PLS $=69$ ), representing poorer life satisfaction. The multivariate adjusted mean difference value of -12.03 represents an effect size of approximately 0.5 of the pooled group standard deviation. This is conventionally defined as a medium effect size, ${ }^{33}$ representing an important or meaningful difference between the two groups.

Veteran and comparison group responses to the WHOQOLBref's two individual measures of self-rated quality of life, and satisfaction with health, are shown in figures 2 and 3 . Veterans were less likely than the comparison group to rate their quality of life as good or very good, and more likely to rate their quality of life as very poor, poor or neither poor nor good. In a similar pattern, veterans were less likely to report being satisfied or very satisfied with their health, and more likely to report being very dissatisfied, dissatisfied or neither dissatisfied nor satisfied.

Mean scores for the WHOQOL-Bref's two individual questions on self-rated quality of life and satisfaction with health, and for the instrument's four domains, are shown in table 1. Veterans had poorer (lower) quality of life scores on all six WHOQOL-Bref measures. The difference between groups on the physical health domain was slightly larger than the differences between groups on the other WHOQOL-Bref domains.

On each of the WHOQOL-Bref measures shown in table 1, the multivariate adjusted mean difference values represent effect sizes of between 0.6 to 0.8 of the pooled group standard deviations. These are considered medium to large effect sizes, ${ }^{33}$ which suggest important or meaningful differences between the two groups on these quality of life measures.

Mean PLS scores for veterans across subgroups of Korean War deployment characteristics are shown in table 2. Decreased life satisfaction (as denoted by decreasing PLS) was most notably associated with increasing levels of combat exposure and decreasing level of rank during the Korean War. Veterans reporting heavy combat exposure had mean PLS scores approximately $15 \%$ lower than veterans reporting no combat. The expected decrease in mean PLS per categorical increase in combat exposure level (eg, from "moderate" to "moderateheavy") was $2.72(p<0.001)$. Veterans who served under enlisted ranks had mean PLS scores approximately 12\% lower than veterans who served as officers. The expected decrease in mean PLS per categorical decrease in rank, from officer to noncommissioned officer to enlisted rank, was $5.00(p<0.001)$.

There was a statistically significant association between increased life satisfaction and service branch (with Air Force veterans reporting highest PLS and Army veterans reporting lowest), older age at deployment and absence of any experience of being wounded in action during Korea, but these effect sizes were small. ${ }^{33}$

While observed associations between increased life satisfaction and increasing duration of deployment, and deployment era after the armistice, reached statistical significance, the total differences in mean PLS scores across subgroups of these deployment characteristics were extremely small. There was no association between life satisfaction and deployment to another major conflict other than the Korean War (not tabulated).

Mean WHOQOL-Bref domain scores were also compared across deployment characteristics. Because the patterns of association between domain scores and deployment characteristics were similar for each of the physical health, psychological health, social relationships and environment domains, only the results for the environment domain have been given in table 2 .

Increasing levels of reported combat exposure were strongly associated with poorer quality of life, as denoted by decreasing 


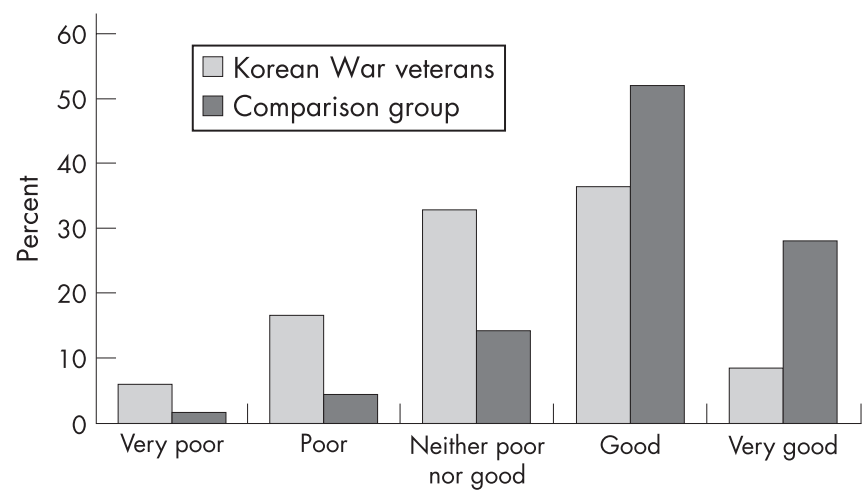

Figure 2 WHOQOL-Bref question 1 "How would you rate your quality of life?"

mean scores on each of the domains of physical health (categorical dose-response score $-0.54, p<0.001$, not tabulated), psychological health $(-0.41, \mathrm{p}<0.001$, not tabulated), social relationships $(-0.33, p<0.001$, not tabulated) and environment $(-0.29, p<0.001$ as shown in table 2$)$. This association was slightly stronger for physical health than for quality of life represented by the other domains. Decreasing rank was also consistently associated with poorer quality of life. The expected decrease in mean domain score per categorical decrease in rank ranged between -0.63 and -0.70 for the four domains (each $\mathrm{p}<0.001$ ).

Other significant associations, although with small effect sizes, were observed between decreasing mean domain scores, army service, increasing duration of deployment, deployment before the armistice and being wounded in action. There was no association between scores on any of the domains and age at deployment, or deployment to another major conflict (this variable is not tabulated).

\section{DISCUSSION}

This study provides evidence that, 50 years after returning from the Korean War, Australia's surviving veterans are experiencing a very low level of life satisfaction and quality of life compared with similarly aged Australian men, and this is strongly associated with the severity of combat experienced during the Korean War and low rank.

With respect to how they feel about their life as a whole, taking into account what has happened in the last year and what is expected to happen in the future, Korean War veterans are more likely than other Australian men to report feeling dissatisfied or unhappy. The veterans' mean PLS score of $56 \%$ is well below the mean of $69 \%$ recorded by the comparison group which, in turn, is consistent with Cummin's (1998) proposed universal norm of $70 \%{ }^{34}$ and Dear et al's (2002) finding of a $70.4 \%$ mean PLS score in Australian adults. ${ }^{23}$

The WHO defines quality of life as "individuals' perceptions of their position in life in the context of the culture and value systems in which they live and in relation to their goals, expectations, standards and concerns". ${ }^{18}$ Using the WHOQOLBref, veterans scored more poorly than the comparison group in relation to their physical health, including ability to perform activities of daily living and mobility, psychological functioning including self-esteem, concentration, negative mood and body image, social relationships including personal relationships and social support, and environment including financial resources, transport, safety and access to information.

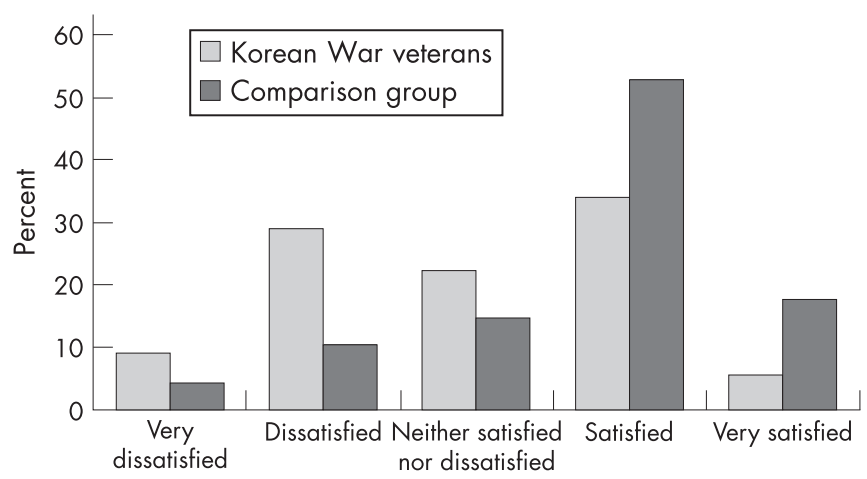

Figure 3 WHOOOL-Bref question 2 "How satisfied are you with your health?"

As lower life satisfaction and well-being have been shown to be closely associated with both physical and mental health, ${ }^{23} 35$ the findings in this study are consistent with previously reported findings of increased mortality, ${ }^{14}$ elevated cancer incidence ${ }^{15}$ and poor psychological health ${ }^{16}$ in Australian Korean War veterans. However, health-related factors alone are not the only factors known to affect current life satisfaction, and may not be the only explanation for the Australian veterans' poor results. While this study was limited to a single-item life satisfaction instrument, the concept of life satisfaction is multifaceted and has been described in terms of morale, positive self-concept, finding life meaningful, pleasure in daily activities, success in achieving major goals and optimism, ${ }^{36}$ and reactions to particular life concerns such as income or housing. ${ }^{37}$ Dear et al (2002) reported associations between life satisfaction and various socioeconomic factors including home ownership and employment status. ${ }^{23}$ Quality of life is also considered a multidimensional subjective assessment measuring not only health issues but also other dimensions of life that might include lifestyle, happiness, adequacy of material circumstances, social relationships and level of freedom. ${ }^{18} 3538$ There was not scope within the current study to investigate veterans' diverse life experiences from the intervening period since the Korean War, both related and unrelated to military service, which may have impacted upon the various dimensions of life satisfaction and quality throughout the life course of this group.

Among the Korean War deployment variables investigated in this study, increasing combat severity and decreasing rank showed the strongest associations with poor life satisfaction and quality. Stress and painful memories associated with combat severity have previously been shown to have a longterm adverse impact upon elderly veterans' psychological ${ }^{3} 3940$ and social well-being. ${ }^{10}{ }^{41}$ Decreasing rank has also previously been shown to be associated with increased morbidity in later life. ${ }^{7}$ Reasons for this association may include personality traits that might vary across ranks such as coping skills or leadership ability, effects of military experiences that might vary across ranks such as type of training, access to strategic information or exposure to dangerous duties, or non-military factors associated with rank such as socioeconomic status. Interestingly, the mean PLS score for officers $(67 \%)$ is very close to that of the comparison group and to previously reported Australian adult ${ }^{23}$ and universal mean results, ${ }^{34}$ and the officers' mean WHOQOLBref environment domain score (16.59; SD 2.23) is slightly better than the comparison group mean (16.24; SD 2.15). These findings suggest little or no long-term adverse effect of Korean 
Table 2 Percentage Life Satisfaction and WH000L-Bref domain 4 (environment) scores for Korean War veterans by deployment characteristics

\begin{tabular}{|c|c|c|c|c|c|c|c|c|c|c|}
\hline & \multicolumn{5}{|c|}{ Percentage Life Satisfaction } & \multicolumn{5}{|c|}{ WHO0OL-Bref domain 4 (environment) score } \\
\hline & $\mathbf{N}$ & Mean & (SD) & $\begin{array}{l}\text { Adjusted mean } \\
\text { difference* }^{*}(95 \% \mathrm{Cl})\end{array}$ & p Value & $\mathbf{N}$ & Mean & (SD) & $\begin{array}{l}\text { Adjusted mean } \\
\text { difference* }^{*}(95 \% \mathrm{CI})\end{array}$ & p Value \\
\hline \multicolumn{11}{|l|}{ Age at deployment } \\
\hline $21-25$ years & 3375 & 55.95 & $(21.41)$ & $2.30(0.73$ to 3.88$)$ & & 3389 & 14.81 & $(2.50)$ & $0.17(-0.01$ to 0.35$)$ & \\
\hline $26-30$ years & 1030 & 58.41 & (21.31) & $2.94(0.46$ to 5.42$)$ & & 1039 & 15.21 & (2.54) & $0.34(0.06$ to 0.63$)$ & \\
\hline$\geqslant 31$ years & 249 & 60.04 & (22.24) & $4.10(-0.80$ to 8.99$)$ & & 247 & 15.20 & (2.31) & $0.20(-0.36$ to 0.77$)$ & \\
\hline Officer & 443 & 67.31 & $(20.40)$ & 0.000 & $<0.001 \dagger$ & 441 & 16.59 & (2.23) & 0.00 & $<0.001 \dagger$ \\
\hline NCO & 1128 & 58.54 & $(21.40)$ & $-7.80(-10.48$ to -5.12$)$ & & 1134 & 15.22 & (2.46) & $-1.04(-1.35$ to -0.74$)$ & \\
\hline Enlisted rank & 4486 & 53.99 & $(21.56)$ & $-11.60(-14.21$ to -9.00$)$ & & 4503 & 14.54 & (2.47) & $-1.61(-1.90$ to -1.31$)$ & \\
\hline Dose-response: & & - & - & $-5.00(-6.09$ to -3.90$)$ & $<0.001$ & & - & - & $-0.70(-0.83$ to -0.58$)$ & $<0.001$ \\
\hline \multicolumn{11}{|l|}{ Service branch } \\
\hline$<6$ months & 1443 & 56.66 & $(22.33)$ & 0.00 & $<0.001 \uparrow$ & 1448 & 15.04 & $(2.50)$ & 0.00 & $<0.001 \dagger$ \\
\hline $6-<12$ months & 2639 & 56.65 & (21.35) & $0.77(-0.63$ to 2.18$)$ & & 2643 & 14.89 & (2.48) & $-0.03(-0.19$ to 0.13$)$ & \\
\hline$\geqslant 12$ months & 1963 & 54.07 & $(21.71)$ & $-1.91(-3.40$ to -0.42$)$ & & 1975 & 14.56 & (2.55) & $-0.35(-0.52$ to -0.18$)$ & \\
\hline Dose-responset & & - & - & $-1.08(-1.82$ to -0.34$)$ & 0.004 & & - & - & $-0.19(-0.27$ to -0.10$)$ & $<0.001$ \\
\hline \multicolumn{11}{|l|}{ Era first deployed } \\
\hline Mobile phase & 1005 & 55.34 & (22.52) & 0.00 & $<0.001 \uparrow$ & 1008 & 14.89 & (2.58) & 0.00 & $0.001 \dagger$ \\
\hline Static phase & 3197 & 55.18 & $(21.86)$ & $0.52(-1.05$ to 2.09$)$ & & 3209 & 14.72 & (2.57) & $-0.09(-0.27$ to 0.09$)$ & \\
\hline After armistice & 1853 & 57.20 & (21.07) & 3.44 (1.66 to 5.22$)$ & & 1859 & 14.96 & (2.38) & $0.20(0.001$ to 0.41$)$ & \\
\hline \multicolumn{11}{|l|}{ Wounded in action } \\
\hline No & 5132 & 56.76 & (21.62) & 0.00 & $<0.001 \dagger$ & 5145 & 14.96 & (2.48) & 0.00 & $<0.001 \dagger$ \\
\hline $\begin{array}{l}\text { Yes, evacuation } \\
\text { type } 1 \text { or } 2\end{array}$ & 429 & 51.05 & $(21.36)$ & $-4.53(-6.68$ to -2.38$)$ & & 433 & 14.13 & (2.66) & $-0.68(-0.92$ to -0.43$)$ & \\
\hline Moderate-heavy & 486 & 50.89 & (21.99) & $-9.89(-12.21$ to -7.56$)$ & & 492 & 14.32 & (2.74) & $-1.06(-1.33$ to -0.80$)$ & \\
\hline Heavy & 148 & 46.17 & $(23.50)$ & $-14.64(-18.30$ to -10.98$)$ & & 148 & 13.59 & $(2.80)$ & $-1.80(-2.21$ to -1.38$)$ & \\
\hline Dose-responset: & & - & - & $-2.72(-3.03$ to -2.13$)$ & $<0.001$ & & - & - & $-0.29(-0.34$ to -0.24$)$ & $<0.001$ \\
\hline
\end{tabular}

NCO, non-commissioned officer.

*These mean differences and their associated $95 \% \mathrm{Cl}$ and $\mathrm{p}$ values, for all dependent measures except wounded in action and CES score, are adjusted for age (65-69 years; $70-$ 74 years; 75-79 years; 80-84 years; $85+$ years), education (primary; any secondary up to grade 10; grades 11, 12 or certificate; diploma or university), marital status (married or de facto; widowered; divorced or separated; single, never married) and country of birth (Australia; other). Results for the dependent measures wounded in action and CES score include additional adjustment for rank in Korea (officer; non-commissioned officer; enlisted rank) and service branch (Navy, Army, Air Force).

$\uparrow$ These $p$ values assess whether any adjusted mean difference within each exposure variable differs from zero.

Dose-response per categorical change in this deployment characteristic.

War service on life satisfaction or quality in this higher ranked group of veterans.

Findings in relation to other war deployment factors are scarce in the elderly veteran literature. Allender et al (2006) reported an association between poor quality of life and possible chemical warfare agent exposure. ${ }^{42}$ Contrary to reports of older war deployment age being associated with later life disadvantage $^{10}$ and service branch being unrelated to later psychological well-being, ${ }^{7}$ we found weak associations between decreased life satisfaction and younger deployment age and service in the Army. Previously reported associations between war-related physical problems and current psychological distress in elderly veterans ${ }^{7}$ may be similar to the association we found between being wounded in action and decreased current life satisfaction.
Unlike many recent studies, which have relied on small, ${ }^{43}$ treatment-seeking ${ }^{29}$ or self-referred veteran groups, ${ }^{7}$ a major methodological strength of this study was the participation by $81 \%$ of the entire surviving Australian male Korean War veteran population resident in Australia. Further, the inclusion of a large community-based comparison group, matched to the Korean War veterans for age range and Australian nationality or residency in Australia at the time of the Korean War, provided an important benchmark against which the well-being of the veterans could be usefully compared. Other methodological strengths include the use of well-validated instruments and access to DVA-held data for some war-related service characteristics in preference to relying exclusively on veterans' recall. Methodological limitations to the study, however, include the 


\section{What is already known on this subject}

Military service is considered a hidden variable underlying current knowledge about ageing, with many major studies of ageing not including veteran status in their investigations. Particularly little is known about the impact of Korean War service on well-being in elderly veteran survivors. Before two recent studies showing increased mortality and cancer incidence in Australian veterans of the Korean War, there were no major investigations of well-being in large groups of this Australian veteran population.

\section{What this study adds}

This study shows that, 50 years after the Korean War, life satisfaction and quality in Australian veterans is poor relative to other Australian men, and associated with deployment-related factors including combat severity and low rank.

\section{Policy implications}

In order to respond effectively to current and projected population health needs, nations with large veteran populations need to consider the impact of military service on well-being in later life.

reliance on self-reported measures and the necessity for retrospective assessment of some deployment-related factors, leaving some study data vulnerable to recall bias.

The study is also limited in part by a lack of baseline health information for the two study groups at the time of the Korean War. It is known, however, that at the time of the Korean War, Australian armed forces volunteers were screened for their fitness to serve. Exclusion criteria included poor health, chronic diseases or serious congenital abnormalities, overt personality problems or behavioural disorders, and IO scores below $80 .{ }^{14} \mathrm{It}$ is possible, therefore, that the Korean War veterans were, on average, in better health than the comparison group at the time of the Korean War. Previous literature suggests that the exclusion of unfit persons from the armed forces can result in a "healthy soldier" effect, which may partly conceal increased morbidity or mortality that should be attributed to war service. ${ }^{44} 45$ If such a "healthy soldier" effect were to exist in our data, this would suggest that the observed group differences, in the direction of poorer well-being in veterans, actually represent an underestimation of the true magnitude of the differences that could be attributed to Korean War service.

While past military experiences and other past events that have shaped the life course of ageing veterans cannot be changed, there may be interventions that can prevent or reduce ongoing suffering in this high-risk group. Low quality of life has been shown to result in increased health care utilisation and mortality; ${ }^{13}$ therefore effective intervention may have considerable future health cost benefits. Consideration of the impact of war service on ageing may assist governments to effectively respond to current and projected population health needs as vast numbers of veterans worldwide move through, and towards, old age.
Acknowledgements: We are grateful to the following groups and individuals: Professors Priscilla Kincaid Smith (Chair), John McNeil and John Zalcberg from the Scientific Advisory Committee; Colonel Alan McDonald (Retd), Rear Admiral Simon Harrington, Major General Paul Stevens and other members of the Consultative Forum representing the veteran and service community; Mr Denis Murphy, Ms Helen Westbury, Ms Di Summerhayes and other project staff at the Australian Government Department of Veterans' Affairs; consultants Dr Philip Boorman and Mr Robert van der Hoek; statistical advisor Associate Professor Andrew Forbes and other Monash University project staff, Mr Anthony Del Monaco, Ms Elsa Barton, Ms Christina Dimitriadis, Ms Anna Davidson and Ms Kate Davidson; and the Korean War veterans and comparison group who freely gave their time to participate in this study.

Funding: Financial support for this research was received from the Australian Government Department of Veterans' Affairs and the National Health and Medical Research Council.

\section{Competing interests: None}

Ethics approval: This study was approved by the Monash University and Australian Government Department of Veterans' Affairs human research ethics committees.

\section{REFERENCES}

1. Andrews K. National strategy for an ageing Australia: community consultations. Canberra: Commonwealth of Australia Report, 2003.

2. Department of Health. A new ambition for old age: next steps in implementing the National Service Framework for older people. London: Department of Health, 2006

3. Spiro IA, Schnurr PP, Aldwin CM. Combat-related posttraumatic stress disorder symptoms in older men. Psychol Aging 1994;9:17-26.

4. Settersten RAJ. When nations call. How wartime military service matters for the life course and aging. Res Aging 2006;28:12-36.

5. American Psychological Association Working Group on the Older Adult. What practitioners should know about working with older adults. Prof Psychol Res Pract 1998;29:413-27.

6. Goulston KJ, Dent OF, Chapuis PH, et al. Gastrointestinal morbidity among World War II prisoners of war: 40 years on. Med J Aust 1985;143:6-10.

7. Hunt $\mathbf{N}$, Robbins I. The long-term consequences of war: the experience of World War II. Aging Ment Health 2001;5:183-90.

8. Bedard $\mathbf{K}$, Deschenes 0 . The long-term impact of military service on health: evidence from World War II and Korean War veterans. Am Econ Rev 2006;96:176-94.

9. Selim AJ, Berlowitz DR, Fincke G, et al. The health status of elderly veteran enrollees in the veterans health administration. J Am Geriatr Soc 2004;52:1271-6.

10. Elder GHJ, Shanahan MJ, Clipp EC. When war comes to men's lives: life-course patterns in family, work and health. Psychol Aging 1994;9:5-16.

11. Lyons MJ, Kremen WS, Franz C, et al. Vietnam service, combat and lifetime educational attainment. Res Aging 2006;28:37-55.

12. Fontana $\mathbf{A}$, Rosenheck R. Traumatic war stressors and psychiatric symptoms among World War II, Korean and Vietnam War veterans. Psychol Aging 1994;9:27-33.

13. Singh JA, Borowsky SJ, Nugent S, et al. Health-related quality of life, functional impairment, and health care utilization by veterans: Veterans' quality of life study. J Am Geriatr Soc 2005:53:108-13.

14. Harrex WK, Horsley KW, Jelfs P, et al. Mortality of Korean War veterans: the veteran cohort study. A report of the 2002 prospective cohort study of Australian veterans of the Korean War. Canberra: Department of Veterans' Affairs, 2003.

15. Australian Institute of Health and Welfare. Cancer Incidence Study 2003: Australian veterans of the Korean War. AlHW Cat. No. PHE 48: Canberra: AlHW, 2003.

16. Ikin JF, Sim MR, McKenzie DP, et al. Anxiety, post-traumatic stress disorder and depression in Korean War veterans fifty years after the war. Br J Psychiatry 2007; 190:475-83.

17. Andrews F, Withey S. Social indicators of well-being: Americans' perception of life quality. New York: Plenum, 1976

18. World Health Organization. WHOOOL-BREF introduction, administration, scoring and generic version of the assessment. Geneva: WHO, December 1996.

19. The WHOQOL Group. Development of the World Health Organization WHOOOLBREF quality of life assessment. Psychol Med 1998;28:551-8.

20. Keane TM, Fairbank JA, Caddell JM, et al. Clinical evaluation of a measure to assess combat exposure. Psychol Assess 1989;1:53-5.

21. Cummins RA. On the trail of the gold standard for subjective well-being. Soc Ind Res 1995;35:179-200.

22. Lehman AF, Ward NC, Linn LS. Chronic mental patients: the quality of life issue. Am J Psychiatry 1982;139:1271-6.

23. Dear K, Henderson S, Korten A. Well-being in Australia: findings from the National Survey of Mental Health and Well-being. Soc Psychiatry Psychiatr Epidemiol 2002;37:503-9

24. Blake DD, Keane TM, Wine PR, et al. Prevalence of PTSD symptoms in combat veterans seeking medical treatment. J Trauma Stress 1990;3:15-27.

25. Blake DD, Cook JD, Keane TM. Post-traumatic stress disorder and coping in veterans who are seeking medical treatment. J Clin Psychol 1992;48:695-704.

26. Engdahl B, Dikel T, Eberly R, et al. Posttraumatic stress disorder in a community group of former prisoners of war: a normative response to severe trauma. Am J Psychiatry 1997;154:1576-81. 
27. Hyer L, Stanger E, Boudewyns P. The interaction of posttraumatic stress disorder and depression among older combat veterans. J Clin Psychol 1999;55:1073-83.

28. Schnurr PP, Spiro A III. Combat exposure, posttraumatic stress disorder symptoms, and health behaviours as predictors of self-reported physical health in older veterans. J Nerv Ment Dis 1999;187:353-9.

29. McCranie EW, Hyer LA. Posttraumatic stress disorder symptoms in Korean conflict and World War II combat veterans seeking outpatient treatment. J Trauma Stress 2000; 13:427-39.

30. SPSS Inc. SPSS for Windows, version 11.5. Chicago, IL: SPSS Inc., 2002.

31. StataCorp. Stata statistical software version 8. College Station, TX: Stata Corporation, 2002.

32. Montgomery DC, Peck EA, Vining GG. Introduction to linear regression analysis, 3rd edn. New York: Wiley, 2001.

33. Cohen J. Statistical power analysis for the behavioral sciences, 2nd edn. Hillsdale, NJ: Erlbaum, 1988

34. Cummins R. The second approximation to an international standard for life satisfaction. Soc Ind Res 1998;43:307-34.

35. Netuveli G, Wiggins RD, Hildon Z, et al. Quality of life at older ages: evidence from the English longitudinal study of ageing (wave 1). J Epidemiol Community Health 2006;60:357-63.

36. Neugarten BL, Havinghurst RJ, Tobin SS. The measurement of life satisfaction. J Gerontol 1961;16:134-43.
37. McDowell I, Newell C. Psychological well-being. In Measuring health: a guide to rating scales and questionnaires, Chapter 5. New York: Oxford University Press, 1996:195.

38. McDowell I, Newell C. General health status and quality of life. In Measuring health a guide to rating scales and questionnaires, 2nd edn. Chapter 9. New York: Oxford University Press, 1996:446-61.

39. Elder GH, Colerick Clipp E. Combat experience and emotional health: impairment and resilience in later life. J Pers 1989;57:311-41.

40. Sutker PB, Allain AN Jr. Assessment of PTSD and other mental disorders in World War II and Korean conflict POW survivors and combat veterans. Psychol Assess 1996;8:18-25.

41. Pavalko EK, Elder GHJ. World War II and divorce: a life course perspective. Am J Sociol 1990;5:1213-34.

42. Allender S, Maconochie N, Keegan T, et al. Symptoms of ill-health and quality of life in a support group of Porton Down veterans. Occup Med 2006:56:329-37.

43. Davison E, Pless A, Gugliucci $M$, et al. Late-life emergence of early life trauma: the phenomenon of late-onset stress symptomatology among aging combat veterans. Res Aging 2006:28:84-114.

44. Guest CS, Venn AJ. Mortality of former prisoners of war and other Australian veterans. Med J Aust 1992;157:132-5.

45. Bros ID, Bros NS. Do atomic veterans have excess cancer? New results correcting for the healthy soldier bias. Am J Epidemiol 1987;126:1042-50. 